Journal of Mechanical Engineering and Sciences

ISSN (Print): 2289-4659; e-ISSN: 2231-8380

Volume 12, Issue 4, pp. 4263-4274, December 2018

(C) Universiti Malaysia Pahang, Malaysia

DOI: https://doi.org/10.15282/jmes.12.4.2018.20.0366

\title{
Economic potential assessment of rare earth extraction sequence based on rule- based framework
}

\author{
M. Y. M. Yunus ${ }^{1 *}$, N. A. Ismail ${ }^{1}$, B. A. Aziz ${ }^{2}$ \\ ${ }^{1}$ Rare Earth Research Centre, Universiti Malaysia Pahang, \\ 26300 Gambang, Pahang, Malaysia \\ Phone: +6095493316; Fax: +6095493312 \\ *Email: yusri@ump.edu.my \\ ${ }^{2}$ Faculty of Bioengineering and Technology, Universiti Malaysia Kelantan, \\ 17600, Jeli, Kelantan, Malaysia
}

\begin{abstract}
Rare Earth Element (REE) is a unique group of metals which mainly comprises seventeen (17) elements, which fifteen (15) elements from the lanthanides group plus Scandium and Yttrium. This REE can be divided into heavy rare earth element (HREE) and light rare earth element (LREE) categories. During the initial extraction stage, the LREE is separated from HREE of the original ore and the sub-separations are then conducted subsequently corresponding to the respective categories. However, the separation difficulty becomes rather critical in a certain context, whenever the HREE is the major element to be extracted relative to LREE. In addition, there are no systematic guidelines procedures available to determine which specific separation pathway is more economically feasible among the various extraction options that exist. Thus, this study proposes a systematic quantitative rule-based framework, by excel modelling, in assessing comprehensively the economic potential of any separation model of REE processing that considered, whereby the standard characterization of monazite mineral composition is utilized as the main case study. This work also adopts the separation factor value of HDEHP-HCL as well as EHEHPA-HCL as the main extraction platforms. The findings suggest that the former extractant is effective for the extraction of light REE (LREE), while the latter incline to prefer the medium and heavy REE (MREE and HREE) particularly on the ground of separation stages factor. In light of the initial results, this study also proposes a hybrid approach in performing the complete optimal REE separation that specifically based on the sequence of 'Art versus Science' (AvsS) structure. These results have demonstrated that the proposed quantitative rule-based framework able to determine the optimal separation pathway provided the complete separation factor values and the mineral characterization of REE are available for assessment. Thus, this new method is suitably applied as a tool or guidelines in the feasibility study of any processing design for REE separation.
\end{abstract}

Keywords: Rare Earth Element; Solvent Extraction Selection; Separation Factor; Art and Science REE Model, Rule-base Method. 


\section{INTRODUCTION}

Rare earth element (REE) is a unique group of metals which consists of 15 elements of lanthanides as well as Scandium (Sc) and Yttrium (Y). Within the lanthanides group, the elements can be further categorized into LREE (La, Ce, Pr, Nd), medium REE - MREE ( $\mathrm{Sm}, \mathrm{Eu}, \mathrm{Gd}$ ) and HREE (Tb, Dy, Ho, Er, Tm, Yb, Lu) groups [1] . This classification is based on their solubility in double salt or extractability towards acidic extractant. Their main role is very crucial particularly in various green-based industries comprising of industrial magnet [2], catalyst [3], glass polishing [4], phosphors (electronic devices) [5], ceramics [6] as well as defense [6]. All REEs are mainly recovered from mining processing which typically involves five major steps - mining (from the ground to crushed ore), milling (beneficiation), hydrometallurgical processing (transforming REE minerals into RE oxides), separation (extracting as well as purifying the individual REE), refinement (adjusting the REEs quality according to a specific technological demand specification) prior to downstream processing [7].

Solvent extraction (SX) is the most practical method for rare earth as it offers simpler extraction setup with lower cost for a larger amount of ores [8]. A basic solvent extraction process includes extraction, scrubbing/ washing, and stripping stages. Like the solvent extraction of other metals, the solvent extraction of rare earth exploits the separation of REEs between two immiscible liquids to separate one or one group of rare earth elements from the others. The extracted REEs depend on the amount of $\mathrm{H}^{+}$, with the highest amount separates the lanthanide series further to the right on the Periodic Table [9]. The extraction process is repeated a few times to increase the concentration of the interest rare earth towards other metals. At the end of the extraction process, the impurities that stay in the aqueous phase transfer to the raffinate output, while the extracted REE in the organic phase that contains the targeted REE as well as some impurities are sent to the scrubbing process.

The REE extraction sequence depends on the concentration and separation factor of the targeted RE [1]. The most influential aspect that contributes to the value of the separation factor of one particular extraction process is the extractant. Di-2ethylhexyl phosphoric acid (HDEHP) and 2-ethylhexyl phosphonic acid mono-2-ethyl hexyl ester (EHEHPA) from the organophosphorus acid group is the most versatile extractant for RE extraction [10,11]. Previous studies also showed that combining HDEHP/EHEHPA with other extractant or complexing agent able to improve the RE extraction with the enhancement coefficient between 1 and 5 [12, 13]. In addition, selecting a combination of RE-extractant with better symmetry and stability significantly improve the extraction and selectivity of the process $[9,14]$.

In practice, the bulk of LREE is separated first from the broad elements of MREE and HREE. This approach is simplified and called as 'Art versus Science' (AvsS) processing structure [15] as shown in Table 1. Steve Mackowski derived this model based on his 30 years' experiences in the rare earth processing industry. The model favors high concentration LREE ore such as monazite and bastnasite ores. Although this model is the most common in the rare earth industry, there is no systematic mechanism available to assess the strength economic feasibility's strength of the chosen separation pathway in compared to the alternative extraction options that exist. The separation difficulty becomes rather critical whenever the main extraction target is the HREE while the concentration of the HREE is lower compared to HREE. Therefore, the extraction process of LREE at the initial steps (as according to the AvsS approach) is unnecessary and may impose wasted resources and investments. The aim of this study is to propose a 
systematic framework for assessing the economic feasibility of the extraction sequence of REE using the rule-based method. The main principle in the feasibility assessment is to maximize the revenue by lowering the operation cost in terms of extraction stages. This principle is translated into a new index and called as 'revenue index', in which a higher value is preferable in which indicates higher income generated corresponding to the particular pathway that selected.

Table 1. Individual REEs extraction step based on AvsS system [15]

\begin{tabular}{cll}
\hline Steps & \multicolumn{1}{c}{ Description } & \multicolumn{1}{c}{ REE Involvement } \\
\hline 1 & Separation of MREO+HREO from the & Ce,La,Pr,Nd,Sm,Eu,Gd,Dy,Ho- \\
& raw mat & Lu \\
2 & Separation of MREO from HREO & Sm,Eu,Gd,Dy,Ho-Lu \\
a & Extraction of Gd from Sm,Eu & Sm,Eu,Gd \\
b & Extraction of Eu from Sm & Sm,Eu \\
c & Extraction of Y from Tb-Lu & Y,Tb-Lu \\
d & Extraction of Dy from Tb,Ho-Lu & Dy,Tb,Ho-Lu \\
3 & Separation of Nd/Pr from Ce-La & La,Ce,Pr,Nd \\
a & Extraction of Pr from Nd & Pr,Nd \\
b & Extraction of Ce from La & $\mathrm{Ce}, \mathrm{La}$ \\
\hline
\end{tabular}

\section{EXPERIMENTAL SET UP}

\section{'Art versus Science' Model: REE Industrial Separation Structure}

From Table 1, the process covers comprehensively all type of REEs separation which can be subdivided into three main pathways - light LREO, medium (MREO) and heavy (HREO) RE oxides, The first step separates MREO and HREO as a bulk from the original raw material input. In the second step, the focus is on extracting the specific elements of MREO from all the HREO components. Steps $2 a$ and $2 b$ concentrate on the individual extraction of MREO, starting with Gd and followed by Eu as well as Sm. Meanwhile, steps $2 \mathrm{c}$ and $2 \mathrm{~d}$ correspond to the separation of HREO element. However, the original description mainly highlights recovery of $Y$ and Dy only, while leaving the other HREO components as residue. This is perhaps due to the proportion of HREO is typically small and it is not economically viable for recovery. The last separation stage (step 3) is focusing on the LREO separation. In this particular phase, the separation operation is divided into two sub-series; recovery of $\mathrm{Pr}$ and $\mathrm{Nd}$ in one hand, while separating on $\mathrm{Ce}$ from La on the other. Therefore, the extraction starts with pre-extracting the Pr and $\mathrm{Nd}$ as a group which also called 'Didymium'. This operation also is practically reasonable because Didymium is known for its unique magnetic character, and thus, the separation mechanism should be designed exclusively. In addition, both Ce and La are usually in high composition, hence, if the Didymium is not effectively removed at the beginning of step 3, then the complexity of attaining high purity of Ce or La at the latter stage becomes harder and the higher separation stages are expected.

\section{Design of Experiment}

Figure 1 and Table 2 show the general proposed procedures and the rule-based frameworks in performing the economic assessment of REE extraction in this study respectively. From Figure 1, the first step involves identifying the characteristics of the 
material feed and the corresponding targeted REE that to be extracted. As a guideline, the targeted REE should be highly in proportion as well as valuable. From Table 2, the rulebased system stated that if insufficient amount of targeted REE is found, then it is advisable to look for other material sources. Next in task 2 (Figure 1), a set of separation factors of extractant is to be determined particularly to extract all the required REEs as according to the steps in AvsS model and the identified feed characterization. The rulebased principle highlighted in Table 2 suggests that extractant with relatively high separation factor on the targeted REE is preferable as this will minimize the separation stages. Then, task 3 (Figure 1) relates to the calculation of the separation stages that required following to the specific extraction sequence as depicted in Table 1. From Table 2 , the rule-based principle signifies that the stages should be rationally small for optimizing the operating cost, otherwise different kind of extractant should be applied. Lastly, task 4 (Figure 1) corresponds on analyzing the economical revenue potential of the targeted REE by means of revenue index (Eq (1)), whereby various process separation routes are considered. In conjunction, the ratio of revenue index of the targeted REE should be rationally as well as comparatively the largest among of the separation options that available in order to critically sustain economically.

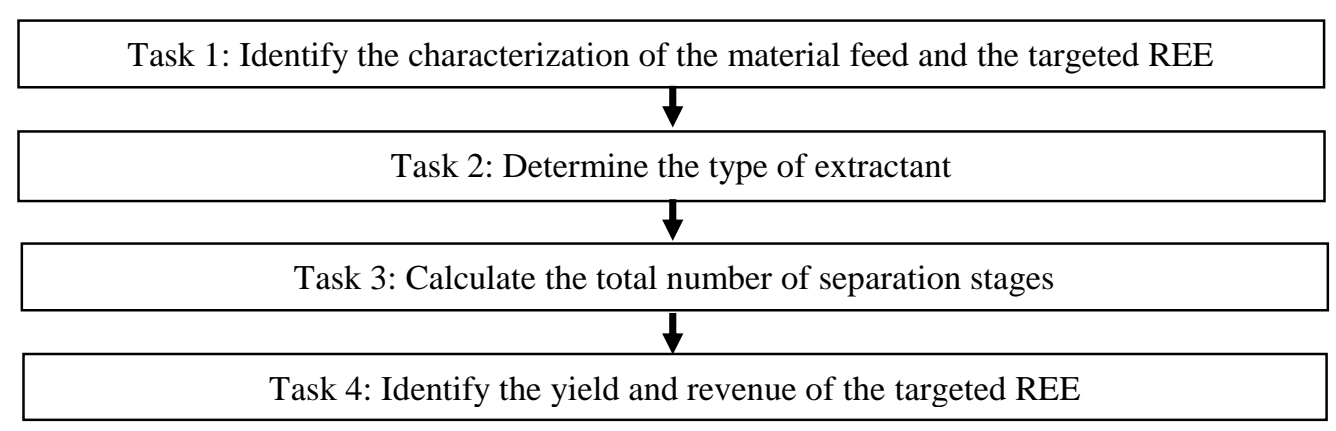

Figure 1. Procedures of assessing the economic potential of the REE extraction

Table 2. Rule-based frameworks of assessing the economic potential of the chosen REEs extraction model.

\begin{tabular}{cl}
\hline Tasks & \multicolumn{1}{c}{ Rule-based Principle } \\
\hline 1 & $\begin{array}{l}\text { IF the targeted REE is relatively high in proportion, THEN large number of } \\
\text { extraction stages is expected, ELSE other feed characterization is required to } \\
\text { sustain the economic viability. }\end{array}$ \\
\hline 2 & $\begin{array}{l}\text { IF the chosen extractant contains relatively high number of separation factor of } \\
\text { the targeted REE, THEN small number of extraction stages is expected, ELSE } \\
\text { other sets of extractant is required. }\end{array}$ \\
\hline 3 & $\begin{array}{l}\text { IF the total number of separation stages of the targeted REE is relatively small } \\
\text { compared to others, THEN the applied extractant is the ideal option, ELSE } \\
\text { different configuration of feed composition and extractant is required. }\end{array}$ \\
\hline 4 & $\begin{array}{l}\text { IF the total revenue index of the targeted REE is relatively huge compared to } \\
\text { others, THEN the sequence of extraction that applied is optimal, ELSE } \\
\text { different separation model is required. }\end{array}$ \\
\hline
\end{tabular}


whereby, $R$ is the revenue in terms of currency

$$
\text { Revenue Index }=\frac{\mathrm{R}}{\mathrm{n}}
$$

$n$ is the total number of separation stages

\section{RESULTS AND DISCUSSION}

The study constraints that implemented in this study is shown as the following: (i) The number of extraction as well as scrubbing stages are determined based on the modelling of counter-current SX operation that developed by Xu and his colleagues [16] . The stages are only corresponding to the first element of every REE group that mentioned in the AvsS hierarchy. This is considered as the initial feasibility analysis prior to robust design which aims to justify the suitability of the selected extractant with the identified raw material characterization. (ii) HDEHP-HCL and RE(III)-HCL-EHEHPA systems [17] are used as the main extractants medium and the source to obtain the separation factor values. (iii) The original REE mineral resource characteristic is based on [1] which has been modified in this study. In the modelling, 1 tonne of feed material is assumed as shown in Table 3; and (iv) All calculations are developed based on the Microsoft Excel platform. (v) The feed capacity is fixed at 1 tonne which composed exclusively of all REEs.

Table 3. Modified monazite characterization of REE mineral obtained originally from [13]

\begin{tabular}{cccccccc}
\hline \multirow{2}{*}{ No. } & \multirow{2}{*}{ REE } & \multicolumn{2}{c}{1 Tonne of Input } & \multirow{2}{*}{ No. } & REE & \multicolumn{2}{c}{1 Tonne of Input } \\
\cline { 3 - 4 } \cline { 7 - 8 } & & Weight, $\mathrm{kg}$ & $\%$ & & & Weight, $\mathrm{kg}$ & $\%$ \\
\hline 1 & $\mathrm{La}$ & 205 & 20.47 & 8 & $\mathrm{~Tb}$ & 5 & 0.48 \\
2 & $\mathrm{Ce}$ & 420 & 42.01 & 9 & $\mathrm{Dy}$ & 27 & 2.71 \\
3 & $\mathrm{Pr}$ & 48 & 4.83 & 10 & $\mathrm{Ho}$ & 6 & 0.56 \\
4 & $\mathrm{Nd}$ & 181 & 18.15 & 11 & $\mathrm{Er}$ & 16 & 0.56 \\
5 & $\mathrm{Sm}$ & 34 & 3.42 & 12 & $\mathrm{Tm}$ & 2 & 0.24 \\
6 & $\mathrm{Eu}$ & 7 & 0.70 & 13 & $\mathrm{Yb}$ & 16 & 1.61 \\
7 & $\mathrm{Gd}$ & 30 & 3.01 & 14 & $\mathrm{Lu}$ & 3 & 0.25 \\
\hline
\end{tabular}

\section{Prioritization of separation complexity based on HDEHP-HCL system}

Table 4 and 5 show the overall results of REE separation based on the structure of AvsS system using the HDEHP-HCL extractant. There are two separations routes - the first route: recovering of the main LREE, MREE and HREE (Table 4), while the second route: extracting of the main LREE only (Table 5). In the first case, the total amount of separation stages which consists of separating HREE, MREE and LREE is 384. The corresponding of REE revenue is found to be USD 14753 per 1 tonne of feed. This gives rise to the revenue index amounting to 38 in ratio. Further looking into the extraction stages, the highest number belongs to the MREE and HREE cases with the total stages close to 236 which equivalent to $61 \%$ of the whole separation stages. In contrary, the separation of the LREE alone produces only $25 \%$ of stages (95 stages), while the rest of $14 \%$ relates to the separation between LREE from HREE and MREE as well as separating MREE from HREE. This finding suggests that separating of MREE and HREE is more complicated compared to LREE. In light of the rule-based principle of Table 2, the second case is considered whereby the targeted REE to be extracted is only on the main LREE 
(due to small number of stages). The outcomes indicate that there are only 113 stages are required for separating LREE, while the corresponding revenue is USD 4990 per 1 tonne of feed. While the revenue has seen almost $66 \%$ reduction from the former route, the revenue index is slightly increased to 44 , which suggests that the latter route is rather optimal. Table 6 demonstrates the analysis outputs of MREE and HREE extraction instead of LREE. In comparing to Table 4, the results of LREE recovery (Table 5) is found to be the ideal solution as it entails the highest revenue index based on the AvsS approach. This finding is found justifiable as the separation factor values of the LREE are found to be relatively higher in contra to MREE and HREE with respect to the HDEHPHCL platform.

\section{Prioritization of separation complexity based on RE(III)-HCL-EHEHPA system}

Table 7 and 8 show the results of applying RE(III)-HCL-EHEHPA extractant which also involves two separation routes - the first route: recovering of the main LREE, MREE and HREE (Table 7), while the second route: extracting of the main HREE only (Table 8). The separation indexes of the first and second cases are 36 and 103 respectively. The second route is considered for HREE extraction instead of LREE (as performed previously by using the HDEHP-HCL medium) because the number of stages on LREE alone comprises of almost $76 \%$ (315 out of 410 - relatively high), hence this particular extractant is not practical for LREE. Interestingly, the revenue index of separating MREE and HREE is significantly large due to relatively higher income revenue generated (USD 9763) and small separation stages (95 steps) compared to LREE revenue index as depicted in Table 9.

In light of this observation, this study suggests that RE(III)-HCL-EHEHPA is preferable particularly for MREE and HREE extraction instead of full recovery of all REE based on the AvsS system. The reason being is that EHEHPA provide better separation factor values especially between the adjacent HREE either in the extraction step or in the selective stripping step compared to DEHPA [18]. The interaction between HREEEHEHPA is also weaker than RE-DEHPA, which makes the scrubbing phase easier in such case $[1,18]$. In addition, the amount of LREE concentrations are typically excessive over other REEs, thus huge extraction stages are normally required relative to MREE and also HREE. Nonetheless, it is shown in Table 7 and 8 that the pricing of MREE and HREE are supremely higher over LREE, hence the revenue index of MREE and HREE in this case is substantially more than that of LREE despite lesser recovery yield. In other words, the revenue index of LREE is incredibly small as highlighted in Table 9 simply due to extremely large number of stages.

Table 4: Economic potential analysis based on HDEHP-HCL extractant for extracting LREE, MREE and HREE

\begin{tabular}{|c|c|c|c|c|c|c|c|}
\hline \multicolumn{8}{|c|}{ RE(III)-HCL-EHEHPA [1] } \\
\hline $\begin{array}{c}\text { Processing } \\
\text { steps }\end{array}$ & Target REE & No. of st & & $\begin{array}{c}\text { Expected } \\
\text { annual } \\
\text { production } \\
\text { capacity, } \\
\mathrm{kg} / \text { year }\end{array}$ & $\begin{array}{c}\text { Price, } \\
\text { USD/ } \\
\text { kg }\end{array}$ & $\begin{array}{c}\text { Expected } \\
\text { annual } \\
\text { revenue, } \\
\text { USD/year }\end{array}$ & $\begin{array}{c}\mathrm{Re} \\
\text { ven } \\
\text { ue } \\
\text { Ind } \\
\text { ex }\end{array}$ \\
\hline \multirow{3}{*}{1} & \multirow{3}{*}{$\begin{array}{c}\text { Mixed MRE } \\
+ \text { HRE (from } \\
\text { LRE) }\end{array}$} & Extraction & 2 & & \multirow{3}{*}{-} & \multirow{3}{*}{ 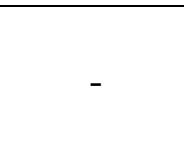 } & \multirow{3}{*}{38} \\
\hline & & Scrubbing & 16 & & & & \\
\hline & & Total & 18 & & & & \\
\hline
\end{tabular}




\begin{tabular}{|c|c|c|c|c|c|c|}
\hline \multirow{3}{*}{2} & \multirow{3}{*}{$\begin{array}{l}\text { Mixed MRE } \\
\text { (from HRE) }\end{array}$} & Extraction & 7 & \multirow{3}{*}{-} & \multirow{3}{*}{ - } & \multirow{3}{*}{-} \\
\hline & & Scrubbing & 28 & & & \\
\hline & & Total & 35 & & & \\
\hline \multirow{3}{*}{$2 \mathrm{a}$} & \multirow{3}{*}{$\begin{array}{c}\text { Gd (from Sm, } \\
\mathrm{Eu})\end{array}$} & Extraction & 13 & \multirow{3}{*}{27} & \multirow{3}{*}{55} & \multirow{3}{*}{1490} \\
\hline & & Scrubbing & 77 & & & \\
\hline & & Total & 90 & & & \\
\hline \multirow{3}{*}{$2 b$} & \multirow{3}{*}{$\mathrm{Eu}($ from Sm) } & Extraction & 78 & \multirow{3}{*}{6} & \multirow{3}{*}{263} & \multirow{3}{*}{1646} \\
\hline & & Scrubbing & 8 & & & \\
\hline & & Total & 86 & & & \\
\hline \multirow{3}{*}{$2 d$} & \multirow{3}{*}{$\begin{array}{c}\text { Dy (from Tb, } \\
\text { Ho-Lu) }\end{array}$} & Extraction & 8 & \multirow{3}{*}{24} & \multirow{3}{*}{272} & \multirow{3}{*}{6627} \\
\hline & & Scrubbing & 52 & & & \\
\hline & & Total & 60 & & & \\
\hline \multirow{3}{*}{3} & \multirow{3}{*}{$\begin{array}{l}\mathrm{Pr}+\mathrm{Nd} \text { (fron } \\
\mathrm{La}+\mathrm{Ce})\end{array}$} & Extraction & 4 & \multirow{3}{*}{-} & \multirow{3}{*}{-} & \multirow{3}{*}{-} \\
\hline & & Scrubbing & 26 & & & \\
\hline & & Total & 30 & & & \\
\hline \multirow{3}{*}{$3 a$} & \multirow{3}{*}{$\operatorname{Pr}($ from Nd) } & Extraction & 32 & \multirow{3}{*}{43} & \multirow{3}{*}{73} & \multirow{3}{*}{3175} \\
\hline & & Scrubbing & 7 & & & \\
\hline & & Total & 39 & & & \\
\hline \multirow{4}{*}{$3 b$} & \multirow{4}{*}{$\mathrm{Ce}$ (from La) } & Extraction & 5 & \multirow{3}{*}{378} & \multirow{3}{*}{5} & \multirow{3}{*}{1815} \\
\hline & & Scrubbing & 21 & & & \\
\hline & & Total & 26 & & & \\
\hline & & $\begin{array}{c}\text { Total } \\
\text { number of } \\
\text { stages }\end{array}$ & 384 & $\begin{array}{r}\text { Total } \\
\text { annua } \\
\text { US }\end{array}$ & & 14753 \\
\hline
\end{tabular}

Prioritization of separation complexity based on HDEHP-HCL and RE(III)-HCLEHEHPA systems - hybrid approach

The results of the previous two cases were revised. The initial findings of both cases suggest that: (i) HDEHP-HCL is effective for LREE separation, while, (ii) RE(III)-HCLEHEHPA is optimally suitable for extracting the MREE as well as HREE. From Figure A, despite that the revenue index of REE full recovery is 44 , however that particular increment is very slightly compared to LREE separation (which indicates value of 38 in ratio). Therefore, the best option of the first extractant should be on separating LREE only and outsourcing the recovery of MREE and HREE. Meanwhile, the separation index of MREE and HREE by using the RE(III)-HCL-EHEHPA medium is significantly large (103 in ratio) as opposed to full recovery (36 in ratio). Thus, the optimum solution for the second extractant should be performing the recovery operation on both MREE and HREE simultaneously, while retain LREE as the residue. 
Table 5: Economic potential analysis based on HDEHP-HCL extractant for extracting LREE

\begin{tabular}{|c|c|c|c|c|c|c|}
\hline \multicolumn{7}{|c|}{ HREE } \\
\hline $\begin{array}{l}\text { Extraction } \\
\text { stages }\end{array}$ & $\begin{array}{l}\text { Scrubbing } \\
\text { stages }\end{array}$ & $\begin{array}{l}\text { Total } \\
\text { stages }\end{array}$ & $\begin{array}{l}\text { Expected annual } \\
\text { production } \\
\text { capacity, } \mathrm{kg} / \mathrm{yr}\end{array}$ & $\begin{array}{c}\text { Price, } \\
\text { USD/kg }\end{array}$ & $\begin{array}{l}\text { Expected annual } \\
\text { revenue, } \\
\text { USD/yr }\end{array}$ & $\begin{array}{l}\text { Revenue } \\
\text { Index }\end{array}$ \\
\hline 2 & 16 & 18 & - & - & - & \multirow{9}{*}{44} \\
\hline 0 & 0 & 0 & - & - & - & \\
\hline 0 & 0 & 0 & 0 & 55 & 0 & \\
\hline 0 & 0 & 0 & 0 & 263 & 0 & \\
\hline 0 & 0 & 0 & 0 & 272 & 0 & \\
\hline 4 & 26 & 30 & - & - & - & \\
\hline 32 & 7 & 39 & 43 & 73 & 3175 & \\
\hline \multirow[t]{2}{*}{5} & 21 & 26 & 378 & 5 & 1815 & \\
\hline & & 113 & & & 4990 & \\
\hline
\end{tabular}

Table 6. Separation stages of MREE and HREE based on AvsS system using HDEHPHCL medium.

\begin{tabular}{cccc}
\hline Steps & $\begin{array}{c}\text { Separation } \\
\text { Stages }\end{array}$ & $\begin{array}{c}\text { Revenue } \\
\text { (USD) }\end{array}$ & $\begin{array}{c}\text { Revenue } \\
\text { Index }\end{array}$ \\
\hline 1 & 18 & - & \\
2 & 35 & - & \\
$2 \mathrm{a}$ & 90 & 1490 & 34 \\
$2 \mathrm{~b}$ & 86 & 1646 & \\
$2 \mathrm{~d}$ & 60 & 6627 & \\
Total & 289 & 9763 & \\
\hline
\end{tabular}

Table 7: Economic potential analysis based on RE(III)-HCL-EHEPA extractant for extracting LREE, MREE and HREE

\begin{tabular}{|c|c|c|c|c|c|c|c|}
\hline \multicolumn{8}{|c|}{ RE(III)-HCL-EHEHPA [1] } \\
\hline $\begin{array}{c}\text { Processing } \\
\text { steps }\end{array}$ & Target REE & \multicolumn{2}{|c|}{ No. of stages } & $\begin{array}{l}\text { Expected } \\
\text { annual } \\
\text { production } \\
\text { capacity, } \\
\mathrm{kg} / \text { year }\end{array}$ & $\begin{array}{l}\text { Price, } \\
\text { USD/ } \\
\text { kg }\end{array}$ & $\begin{array}{l}\text { Expected } \\
\text { annual } \\
\text { revenue, } \\
\text { USD/year }\end{array}$ & $\begin{array}{l}\text { Revenue } \\
\text { Index }\end{array}$ \\
\hline \multirow{3}{*}{1} & \multirow{3}{*}{$\begin{array}{c}\text { Mixed MRE } \\
+ \text { HRE (from } \\
\text { LRE) } \\
\end{array}$} & Extraction & 1 & \multirow[t]{3}{*}{-0.5} & \multirow{3}{*}{-} & \multirow{3}{*}{ - } & \multirow{11}{*}{36} \\
\hline & & Scrubbing & 6 & & & & \\
\hline & & Total & 7 & & & & \\
\hline \multirow{3}{*}{2} & \multirow{3}{*}{$\begin{array}{l}\text { Mixed MRE } \\
\text { (from HRE) }\end{array}$} & Extraction & 1 & & & & \\
\hline & & Scrubbing & 6 & - & - & - & \\
\hline & & Total & 7 & & & & \\
\hline \multirow{3}{*}{$2 \mathrm{a}$} & \multirow{3}{*}{$\begin{array}{c}\text { Gd (from Sm, } \\
\text { Eu) }\end{array}$} & Extraction & 25 & & & & \\
\hline & & Scrubbing & 4 & 27 & 55 & 1490 & \\
\hline & & Total & 29 & & & & \\
\hline \multirow{2}{*}{$2 b$} & \multirow{2}{*}{$\mathrm{Eu}($ from $\mathrm{Sm}$ ) } & Extraction & 4 & \multirow{2}{*}{6} & \multirow{2}{*}{263} & \multirow{2}{*}{1646} & \\
\hline & & Scrubbing & 31 & & & & \\
\hline
\end{tabular}




\begin{tabular}{|c|c|c|c|c|c|c|}
\hline & & Total & 35 & & & \\
\hline \multirow{3}{*}{$2 d$} & \multirow{3}{*}{$\begin{array}{c}\text { Dy (from Tb, } \\
\text { Ho-Lu) }\end{array}$} & Extraction & 15 & \multirow{3}{*}{24} & \multirow{3}{*}{272} & \multirow{3}{*}{6627} \\
\hline & & Scrubbing & 2 & & & \\
\hline & & Total & 17 & & & \\
\hline \multirow{3}{*}{3} & \multirow{3}{*}{$\begin{array}{l}\mathrm{Pr}+\mathrm{Nd}(\text { fron } \\
\mathrm{La}+\mathrm{Ce})\end{array}$} & Extraction & 10 & \multirow{3}{*}{-} & \multirow{3}{*}{-} & \multirow{3}{*}{ - } \\
\hline & & Scrubbing & 77 & & & \\
\hline & & Total & 87 & & & \\
\hline \multirow{3}{*}{$3 a$} & \multirow{3}{*}{$\operatorname{Pr}($ from $\mathrm{Nd})$} & Extraction & 134 & \multirow{3}{*}{43} & \multirow{3}{*}{73} & \multirow{3}{*}{3175} \\
\hline & & Scrubbing & 16 & & & \\
\hline & & Total & 150 & & & \\
\hline \multirow{4}{*}{$3 b$} & \multirow{4}{*}{$\mathrm{Ce}$ (from La) } & Extraction & 65 & \multirow{3}{*}{378} & \multirow{3}{*}{5} & \multirow{3}{*}{1815} \\
\hline & & Scrubbing & 13 & & & \\
\hline & & Total & 78 & & & \\
\hline & & $\begin{array}{c}\text { Total } \\
\text { number of } \\
\text { stages }\end{array}$ & 410 & $\begin{array}{l}\text { Total } \\
\text { annua } \\
\text { US }\end{array}$ & ted & 14753 \\
\hline
\end{tabular}

However, if one insists on the full recovery of the whole REE spectrums based on the AvsS structure, then the possible as well as practical solution should be utilizing both of the extractants in two separate production phases. Table 10 denotes the results of economic potential assessment of REE extraction using hybrid extractant application.

In the first phase, the focus should be on recovering the MREE as well as HREE by using RE(III)-HCL-EHEHPA system that covering of steps 1, 2, 2a, 2b and 2c. While in the second phase, the HDEHP-HCL medium should then be employed particularly to extract the LREE compnents. Interestingly, the outcomes of the revenue index from Figure 3 based on the hybrid approach (Analysis $A+B-Z$ ) is superior (78 in ratio) against of that either LREE or MREE/HREE separations from Table 4 and 7 previously (38 and 36 in ratio respectively). The higher revenue index that shown in Table 10 justifies that the full REE recovery can be conducted optimally by using the combination of two (2) different extractants in two phases of operations instead of merely depending on a single extractant. 
Table 8 : Economic potential analysis based on RE(III)-HCL-EHEPA extractant for extracting HREE

\begin{tabular}{|c|c|c|c|c|c|c|}
\hline \multicolumn{7}{|c|}{ HREE } \\
\hline $\begin{array}{c}\text { Extractio } \\
\text { n stages }\end{array}$ & $\begin{array}{l}\text { Scrubbin } \\
\text { g stages }\end{array}$ & $\begin{array}{c}\text { Total } \\
\text { stages }\end{array}$ & $\begin{array}{c}\text { Expected } \\
\text { annual } \\
\text { production } \\
\text { capacity, } \mathrm{kg} / \mathrm{yr}\end{array}$ & $\begin{array}{c}\text { Price, } \\
\text { USD/kg }\end{array}$ & $\begin{array}{c}\text { Expected } \\
\text { annual } \\
\text { revenue, } \\
\text { USD/yr }\end{array}$ & $\begin{array}{c}\text { Revenue } \\
\text { Index }\end{array}$ \\
\hline 1 & 6 & 7 & - & - & - & \multirow{9}{*}{103} \\
\hline 1 & 6 & 7 & - & - & - & \\
\hline 25 & 4 & 29 & 27 & 55 & 1490 & \\
\hline 4 & 31 & 35 & 6 & 263 & 1646 & \\
\hline 15 & 2 & 17 & 24 & 272 & 6627 & \\
\hline 0 & 0 & 0 & - & - & - & \\
\hline 0 & 0 & 0 & - & 73 & - & \\
\hline 0 & 0 & 0 & 0 & 5 & 0 & \\
\hline & & 95 & & & 9763 & \\
\hline
\end{tabular}

Table 9. Separation stages of LREE based on AvsS system using RE(III)-HCLEHEHPA medium

\begin{tabular}{cccc}
\hline Steps & $\begin{array}{c}\text { Separation } \\
\text { Stages }\end{array}$ & $\begin{array}{c}\text { Revenue } \\
\text { (USD) }\end{array}$ & $\begin{array}{c}\text { Revenue } \\
\text { Index }\end{array}$ \\
\hline 1 & 7 & - & \\
3 & 87 & - & \\
$3 \mathrm{a}$ & 150 & 3175 & 15 \\
$3 \mathrm{~b}$ & 78 & 1815 & \\
Total & 322 & 4990 & \\
\hline
\end{tabular}

Table 10: Economic potential analysis based on hybrid applications of HDEHP-HCL and RE(III)-HCL-EHEPA extractants for extracting LREE, MREE and HREE

\begin{tabular}{|c|c|c|c|c|c|c|c|}
\hline \multicolumn{8}{|c|}{ RE(III)-HCL-EHEHPA [1] } \\
\hline $\begin{array}{c}\text { Processing } \\
\text { steps }\end{array}$ & Target REE & No. of st: & & $\begin{array}{l}\text { Expected } \\
\text { annual } \\
\text { production } \\
\text { capacity, } \\
\text { kg/year }\end{array}$ & $\begin{array}{l}\text { Price, } \\
\text { USD/ } \\
\text { kg }\end{array}$ & $\begin{array}{l}\text { Expected } \\
\text { annual } \\
\text { revenue, } \\
\text { USD/year }\end{array}$ & $\begin{array}{l}\text { Revenue } \\
\text { Index }\end{array}$ \\
\hline \multirow{3}{*}{1} & \multirow{3}{*}{$\begin{array}{c}\text { Mixed MRE } \\
+ \text { HRE (from } \\
\text { LRE) }\end{array}$} & Extraction & 1 & \multirow{3}{*}{ - } & \multirow{3}{*}{ - } & \multirow{3}{*}{-} & \multirow{8}{*}{78} \\
\hline & & Scrubbing & 6 & & & & \\
\hline & & Total & 7 & & & & \\
\hline \multirow{3}{*}{2} & \multirow{3}{*}{$\begin{array}{l}\text { Mixed MRE } \\
\text { (from HRE) }\end{array}$} & Extraction & 1 & \multirow{3}{*}{ - } & \multirow{3}{*}{ - } & \multirow{3}{*}{-} & \\
\hline & & Scrubbing & 6 & & & & \\
\hline & & Total & 7 & & & & \\
\hline \multirow{2}{*}{$2 \mathrm{a}$} & \multirow{2}{*}{$\begin{array}{l}\text { Gd (from Sm, } \\
\text { Eu) }\end{array}$} & Extraction & 25 & \multirow{2}{*}{27} & \multirow{2}{*}{55} & \multirow{2}{*}{1490} & \\
\hline & & Scrubbing & 4 & & & & \\
\hline
\end{tabular}




\begin{tabular}{|c|c|c|c|c|c|c|}
\hline & & Total & 29 & & & \\
\hline \multirow{3}{*}{$2 b$} & \multirow{3}{*}{$\mathrm{Eu}$ (from Sm) } & Extraction & 4 & \multirow{3}{*}{6} & \multirow{3}{*}{263} & \multirow{3}{*}{1646} \\
\hline & & Scrubbing & 31 & & & \\
\hline & & Total & 35 & & & \\
\hline \multirow{3}{*}{$2 d$} & \multirow{3}{*}{$\begin{array}{c}\text { Dy (from Tb, } \\
\text { Ho-Lu) }\end{array}$} & Extraction & 15 & \multirow{3}{*}{24} & \multirow{3}{*}{272} & \multirow{3}{*}{6627} \\
\hline & & Scrubbing & 2 & & & \\
\hline & & Total & 17 & & & \\
\hline \multirow{3}{*}{3} & \multirow{3}{*}{$\begin{array}{c}\mathrm{Pr}+\mathrm{Nd} \text { (fron } \\
\mathrm{La}+\mathrm{Ce})\end{array}$} & Extraction & 4 & \multirow{3}{*}{-} & \multirow{3}{*}{-} & \multirow{3}{*}{-} \\
\hline & & Scrubbing & 26 & & & \\
\hline & & Total & 30 & & & \\
\hline \multirow{3}{*}{$3 a$} & \multirow{3}{*}{$\operatorname{Pr}($ from $\mathrm{Nd})$} & Extraction & 32 & \multirow{3}{*}{43} & \multirow{3}{*}{73} & \multirow{3}{*}{3175} \\
\hline & & Scrubbing & 7 & & & \\
\hline & & Total & 39 & & & \\
\hline \multirow{4}{*}{$3 b$} & \multirow{4}{*}{$\mathrm{Ce}$ (from La) } & Extraction & 5 & \multirow{3}{*}{378} & \multirow{3}{*}{5} & \multirow{3}{*}{1815} \\
\hline & & Scrubbing & 21 & & & \\
\hline & & Total & 26 & & & \\
\hline & & $\begin{array}{c}\text { Total } \\
\text { number of } \\
\text { stages }\end{array}$ & 190 & \multicolumn{2}{|c|}{$\begin{array}{c}\text { Total expected } \\
\text { annual revenue, } \\
\text { USD/year }\end{array}$} & 14753 \\
\hline
\end{tabular}

\section{CONCLUSION}

The AvsS separation model is adopted and analyzed in this study particularly for conducting the REE recovery consisting of LREE, MREE and HREE. Two forms of extractants are employed - HDEHP-HCL and RE(III)-HCL-EHEHPA, whereby the raw material characterization is obtained based on the standard monazite composition (with slight modification by this study). The results demonstrate that by correctly integrating both of the extractants (hybrid approach) in performing the full REE separation gives rise to an optimal solution, which has been identified on the ground of separation index following the hierarchy steps of AvsS system. This can be only realized whenever such rule-based principle that applied by means of revenue index which introduced in this study is fully implemented.

\section{ACKNOWLEDGEMENTS}

The authors would like to be obliged to Universiti Malaysia Pahang for providing laboratory facilities and financial assistance under project no. RDU160350.

\section{REFERENCES}

[1] Zhang, J., B. Zhao, and B. Schreiner, Separation hydrometallurgy of rare earth elements. 2016: Springer International Publishing. 259.

[2] Munchen, D.D. and H.M. Veit, Neodymium as the main feature of permanent magnets from hard disk drives (HDDs). Waste Management, 2017. 61: p. 372276.

[3] Math, M.C. and M.S. Manjunath, Development and characterization of cerium oxide catalyst supported on ceramic honeycomb substrate to reduce emissions of 
spark ignition engine. Journal of Mechanical Engineering and Sciences, 2016. 10(2): p. 1956-1967.

[4] Huang, L.M., Z.Q. Hao, and T. Xiao, Preparation of ultra fine fluorine-containing and ceria-based polishing powder by coprecipitation method. Chinese Rare Earth, 2016. 37(3): p. 100-104.

[5] Salleh, M.N.M., et al., A study on bead-on-plate welding of AA7075 using low power fiber laser. Journal of Mechanical Engineering and Sciences, 2016. 10(2): p. 2065-2075.

[6] Hongxia, Z., et al., Influence of rare earth ions on metal ions distribution and corrosion behavior of tailing-derived glass-ceramics. Journal of Non-Crystalline Solids, 2018. 482: p. 105-115.

[7] Artem, G., et al., Rare earths supply chains: Current status, constraintsand opportunities. Resources Policy, 2014. 41: p. 52-59.

[8] Peppard, D.F., et al., Fractional extraction of the lanthanides as their di-alkyl orthophosphates. Journal of Inorganic and Nuclear Chemistry, 1957. 4(5-6): p. 334-343.

[9] Chang, H., et al., Study on separation of rare earth elements in complex system. Journal of Rare Earth, 2010. 28: p. 116-119.

[10] Feng, X., et al., A critical review on solvent extraction of rare earths from aqueous solutions. Minerals Engineering, 2014. 56: p. 10-28.

[11] Dongbei, W., Z. Qian, and B. Borong, Solvent extraction of Pr and Nd (III) from chloride-acetate medium by 8-hydroquinoline with and without 2-ethylhexyl phosphoric acid mono-2-ethylhexyl ester as an added synergist in heptane diluent. Hydrometallurgy, 2007. 88(1-4): p. 210-215.

[12] Luo, X., et al., Synergistic extraction of cerium from sulfuric acid medium using mixture of 2-ethylhexyl phosphonic acid mono 2-ethylhexyl ester and Di-(2-ethyl hexyl)phosphoric acid as extractant. Journal of Rare Earth, 2009. 27(1): p. 119122.

[13] Can, Z., et al., Yttrium extraction from chloride solution with a synergistic system of 2-ethylhexyl phosphonic acid mono-(2-ethylhexyl) ester and bis(2,4,4trimethylpentyl) phosphinic acid. Hydrometallurgy, 2014. 147-148: p. 7-12.

[14] Li, C., et al., Comprehensive appraisal and application of novel extraction system forheavy rare earth separation on the basis of coordination equilibrium effect. Hydrometallurgy, 2016. 165: p. 351-357.

[15] Steve, M. Separation of Rare Earths - Art vs. Science. 2014 [cited 2017 20-022018]; Available from: https://investorintel.com/sectors/technologymetals/technology-metals-intel/separation-rare-earths-art-vs-science/.

[16] Xu, G., B. Li, and C. Yian, Theory of countercurrent extraction and its application. New Frontier in Rare Earth and Applications, 1985. 2: p. 429-436.

[17] Taichi, S., Liquid-liquid extraction of rare-earth elements from aqueous acid solutions by acid organophosphorus compounds. Hydrometallurgy, 1989. 22(12).

[18] Renata, D.A. and A.M. Carlos, Study on separation of heavy rare earth elements by solvent extraction with organophosphorus acids and amine reagents. Minerals Engineering, 2014. 61: p. 82-87. 